\title{
KONSEP NATION-STATE DALAM PEMIKIRAN IDEOLOGI POLITIK MELAYU ISLAM PADA ABAD KE-19 M (Studi Pemikiran Abdullah bin Abdul Kadir Munsyi (1787-1854))
}

\author{
Andi Chandra Jaya \\ Fakultas Ilmu Sosial dan Ilmu Politik, UIN Raden Fatah Palembang \\ andicandrajaya72@gmail.com
}

Diterima: 02 Maret 2019 Disetujui: 10 Juni 2019 Dipublikasikan: 23 Juni 2019

\begin{abstract}
This study seeks to explore and explore the concept of political ideology of Abdullah bin Abdul Kadir Munsyi in the 19th century AD In this century the socio-political and socio-religious conditions of Malay society were experiencing intellectual transformation involving an intellectual network and Abdullah Munsyi who lived in this century, certainly entered the vortex of intellectual tradition at that time. Then what is equally interesting is the penetration of Europeans (Dutch and English) who were holding colonization in Malay. Therefore, the focus of this study is to answer the subject matter of how the concept of the nation-state according to Abdullah Munsyi in the constellation of Malay Islamic political ideology in the 19th century $\mathrm{AD}$ and is the relevance of the concept of the current Indonesian nation state.In accordance with the problem, the purpose of this study is to get a historical explanation to reveal the nation-state concept according to Abdullah Munsyi in the constellation of Malay Islamic political ideology in the 19th century $\mathrm{AD}$ and describe the relevance of the concept of the current Indonesian nation state. The study used the conscience morale theory of Ernest Renan and the social contract theory initiated by J. J. Roussae. This research is included in the library research category and uses historical approaches and political philosophy. The primary data in this study are Abdullah Musnyi's Hikayat Abdullah book published by Yayasan Karyawan, Kuala Lumpur, Malaysia in 2007 and secondary data, in
\end{abstract}




\section{Andi Chandra Jaya: KONSEP NATION STATE .....}

the form of books, journal articles, papers, and others related to research problems. As historical research, which basically relies on historical sources as an implementation of the stages of activities covered in historical methods, namely heuristics, criticism, interpretation, and historiography. The findings of the research are: 1). In accordance with the theory of conscience morale Ernest Renan and the social contract theory initiated by J. J. Roussae, Abdullah bin Abdul Kadir Munsyi was the originator of nationalism. Through his most important work, Hikayat Abdullah, he put forward the formulation of Malay identity in the formulation of the nation which was understood as a Malay tribe or race who had the right to be involved in determining the Malay political format not as a community under a political system that was authoritarian. 2). His closeness with the British colonial side, thus forming the liberal thinking he obtained from Raffles and his friends. He not only dismantled the manipulation of royal ideology, but at the same time put forward a new view of the existence of a humanist individual. 3). The understanding of nationality has egalitarian values that are very relevant to the current Indonesian context, especially the values of equality (egalitarianism) in the midst of the emergence of conflicts in various conflicts today. Likewise the concept of nation-state is closely related to nationalism and good governance where good governance is based on the absolute existence of transparency, open participation, and accountability in all state activities at every level of state management, so that a clean government is formed.

Keywords: Abdullah Munsyi, Nation-State, and Malay Political Ideology

\section{Abstrak}

Penelitian ini berupaya untuk menggali dan menelusuri konsep pemikiran ideologi politik Abdullah bin Abdul Kadir Munsyi pada abad ke-19 M. Pada abad ini kondisi sosial-politik dan sosio-religius 
masyarakat Melayu sedang mengalami tranformasi intelektual yang melibatkan sebuah jaringan intelektual dan Abdullah Munsyi yang hidup di abad ini, tentunya masuk dalam pusaran tradisi intelektual di masa itu. Kemudian yang tak kalah menarik adalah adanya penetrasi bangsa Eropa (Belanda dan Inggris) yang sedang mengadakan penjajahan di Melayu. Karena itu, fokus penelitian ini untuk menjawab pokok permasalahan konsep nation-state menurut Abdullah Munsyi dalam konstelasi ideologi politik Melayu Islam di abad ke-19 M dan relevansinya konsep negara bangsa Indonesia saat ini. Sesuai dengan permasalahan, maka tujuan penelitian ini mendapatkan eksplanasi sejarah untuk mengungkapkan konsep nation-state menurut Abdullah Munsyi dalam konstelasi ideologi politik Melayu Islam di abad ke-19 M dan mendeskripsikan relevansinya konsep negara bangsa Indonesia saat ini. Penelitian menggunakan teori conscience morale Ernest Renan dan teori kontrak sosial (social contract) yang digagas oleh J. J. Roussae. Penelitian ini termasuk dalam kategori penelitian kepustakaan (library research) dan menggunakan pendekatan historis dan filsafat politik. Data primer dalam penelitian ini adalah buku Hikayat Abdullah karya Abdullah Munsyi terbitan Yayasan Karyawan, Kuala Lumpur, Malaysia tahun 2007 dan data sekunder, berupa buku, artikel jurnal, makalah, dan lainya yang berhubungan dengan masalah penelitian. Sebagai penelitian sejarah yang pada dasarnya bertumpu pada sumber-sumber sejarah sebagai implementasi dari tahapan kegiatan yang tercakup dalam metode sejarah, yaitu heuristik, kritik, interpretasi, dan historiografi. Temuan hasil penelitian adalah: 1). Sesuai dengan teori conscience morale Ernest Renan dan teori kontrak sosial (social contract) yang digagas oleh J. J. Roussae, Abdullah bin Abdul Kadir Munsyi penggagas paham kebangsaan. Melalui karya terpentingnya, Hikayat Abdullah, ia mengedepankan rumusan identitas Melayu dalam rumusan bangsa yang dipahami sebagai suku atau ras Melayu yang memiliki hak untuk terlibat menentukan format politik Melayu bukan sebagai komunitas yang berada di bawah sistem politik yang berbasis pada ideologi kerajaan yang cenderung otoriter. 2). Kedekatannya dengan pihak 
kolonial Inggris, sehingga membentuk pemikiran liberal yang diperolehnya dari Raffles dan kawan-kawannya. Ia tidak hanya membongkar manipulasi ideologi kerajaan, tetapi sekaligus mengedepankan pandangan baru tentang eksistensi individu yang humanis. 3). Paham kebangsaannya memiliki nilai egalitarian yang sangat relevan dengan konteks Indonesia saat ini, khususnya nilainilai kesetaraan (egalitarianisme) di tengah munculnya konflik berbagai konflik saat ini. Demikian juga konsep nation-state terkait erat dengan nasionalisme dan good governance di mana pengelolaan pemerintahan yang baik, yang bertumpu kepada kemutlakan adanya transparansi, partisipasi terbuka, dan pertanggung jawaban di dalam semua kegiatan kenegaraan di setiap jenjang pengelolaan negara, sehingga terbentuk pemerintahan yang bersih.

(C) 2019 Islamic Political Sains Department, UIN Raden Intan Lampung, Indonesia

\section{Kata Kunci: Abdullah Munsyi, Nation-State, dan Ideologi Politik Melayu.}

\section{A. Pendahuluan}

Memasuki abad ke-19 M tradisi intelektual Islam di dunia Melayu mengalami penguatan pemikiran, terutama menyangkut orientasi ideologi politik. ${ }^{1}$ Ketika itu setidaknya terdapat dua orientasi ideologi yang berkembang. Pertama, ideologi politik restorasi kerajaan yang menghendaki model kerajaan Melayu sebelumnya sebagai sistem sosial dan politik rakyat Melayu yang digagas oleh Raja Ali Haji. ${ }^{2}$ Kedua, paham kebangsaan Melayu (nation-state) yang dimotori

${ }^{1}$ Lihat Jajat Burhanuddin, "Tradisi Keilmuan dan Intelektual" dalam Taufik Abdullah (ed), Ensiklopedi Tematik Dunia Islam, Asia Tenggara" (Jakarta: Ichtiar Baru Van Hoeve, 2002), hlm. 160.

${ }^{2}$ Lihat Jajat Burhanuddin, "Tradisi Keilmuan dan Intelektual”, hlm. 161. 


\section{Andi Chandra Jaya: KONSEP NATION STATE}

\section{Abdullah bin Abdul Kadir Munsyi melalui karyanyaHikayat Abdullah ${ }^{3}$.}

Pemikiran Abdullah Munsyi tentang konsep kebangsaan Melayu (nation-state) bila dilihat dari pandangan ideologi politik dapat dimengerti sebagai negara yang penduduknya memandang diri mereka sebagai suatu bangsa. Ia merupakan entitas legal yang memiliki garis-garis batas geografis di bawah pemerintahan tunggal yang penduduk di dalamnya memandang diri mereka sebagai saling berkaitan satu sama lain. ${ }^{4}$ Negara bangsa adalah suatu gagasan tentang negara yang didirikan untuk seluruh bangsa atau untuk seluruh umat, berdasarkan kesepakatan bersama yang menghasilkan hubungan kontraktual dan transaksional terbuka antara pihak-pihak yang mengadakan kesepakatan itu. ${ }^{5}$

Bila dikaji lebih mendalam konsep negara bangsa adalah konsep tentang negara modern yang terkait erat dengan paham kebangsaan (nasionalisme). Menurut Soerjono Soekanto mengemukakan bahwa sebuah Negara bisa dikatakan modern apabila memiliki syarat-syarat tertentu, yaitu cara berpikir yang ilmiah yang berlembaga dalam kelas penguasa ataupun masyarakat, sistem administrasi negara yang baik, yang benar-benar mewujudkan birokrasi, adanya sistem pengumpulan data yang baik dan teratur yang terpusat pada suatu lembaga atau badan tertentu, penciptaan iklim yang menyenangkan dan masyarakat terhadap modernisasi dengan

${ }^{3}$ Amin Sweeney, Karya Lengkap Abdullah bin Abdul Kadir Munsyi, Jilid 1-3 (Jakarta: Kepustakaan Populer Gramedia bekerjasama dengan Ecole francais d'Extreme-Orient, 2005).

${ }^{4}$ Daniel S. Papp, Contemporary International Relations: Framework for Understanding (London: Macmillan Publishing Company, 2nd edition, 1988), hlm. 19.

${ }^{5}$ Nurcholis Madjid, Indonesia Kita,(Jakarta: Paramadina, 2004), hlm. 42. 
cara penggunaan alat-alat komunikasi massa, tingkat organisasi yang tinggi yang di satu pihak berarti disiplin, sedangkan di lain pihak berarti pengurangan kemerdekaan, dan sentralisasi wewenang dalam pelaksanaan perencanaan sosial.

Konsepsi negara bangsa mutlak memerlukan good governance, pengelolaan yang baik, yang bertumpu kepada kemutlakan adanya transparansi, partisipasi terbuka, dan pertanggung jawaban di dalam semua kegiatan kenegaraan di setiap jenjang pengelolaan negara sehingga terbentuk pemerintahan yang bersih. ${ }^{6}$ Good governance menunjuk pada pengertian bahwa kekuasaan tidak lagi semata-mata dimiliki atau menjadi urusan pemerintah, tetapi menekankan pada pelaksanaan fungsi pemerintahan secara bersamasama oleh pemerintah, civil society, dan pihak swasta. Good governance juga berarti implementasi kebijakan sosial-politik untuk kemaslahatan rakyat banyak, bukan hanya untuk kemakmuran orangper-orang atau kelompok tertentu. ${ }^{7}$

Di sinilah, penelitian ini menjadi penting bila dikontekstualisakan dengan kondisi politik di Indonesia. Saat ini bangsa Indonesia telah terjadi krisis identitas. Identitas nasional pada hakikatnya merupakan "manifestasi nilai-nilai budaya yang tumbuh dan berkembang dalam aspek kehidupan suatu nation (bangsa) dengan

${ }^{6}$ Nurcholis Madjid, Indonesia Kita, hlm. 75.

${ }^{7}$ Lihat Lalolo Krina. Indikator Dan Tolok Ukur Akuntabilitas, Traansparansi dan Partisipasi, (Jakarta: Sekretariat Pengembangan Kebijakan Nasional Tata Kepemrintahan yang Baik, BAPPENAS, 2003), hlm.6. 
ciri-ciri khas, dan dengan cirikhas itu setiap bangsa berbeda dengan bangsa lain dalam menata kehidupannya". ${ }^{8}$

Krisis identitas nasional dan keterpurukan bangsa Indonesia saat ini disinyalir karena sebagian besar penguasa dan politisi negeri ini berorientasi pada politik kekuasaan. Seperti diungkapkan Firmanzah bahwa dalam pragmatisme politik yang menjadi penting adalah kekuasaan. Sehingga partisipasi poltik hanya menifestasi dari keinginan untuk berkuasa. Karena dorongan berkuasa begitu kuat, kekuasaan menjadi tujuan akhir dari berpolitik, sehingga mengabaikan kepentingan rakyat Indonesia ${ }^{9}$

Tentunya kondisi demikian tidak ingin terus menerus terjadi. Di sinilah kita perlu menggali kembali khasanah politik Islam Melayu abad ke-19 M, yakni konsep pemikiran nation-stateAbdullah Munsyi (1787-1854). Sebab perjalanan bangsa Indonesia sejak beberapa abad yang lalu menunjukkan adanya pengaruh signifikan dari kebudayaan Melayu. Salah satu sumbangan terbesar adalah turut mewujudkan dan membentuk jati diri dan identitas bangsa Indonesia. Tak berlebihan apabila akhirnya kebudayaan Melayu disebut sebagai akar jati diri bangsa ini.

Fokus penelitian ini untuk menjawab pokok permasalahan konsep nation-state menurut Abdullah Munsyi dalam konstelasi ideologi politik Melayu Islam di abad ke-19 M dan relevansinya konsep negara bangsa Indonesia saat ini

Penelitian ini memiliki tujuan yang tak terpisahkan dengan pokok permasalahan di atas. Sesuai dengan fokus penelitian ini, maka

8"Krisis Identitas Bangsa", dalam http://projectcitizenship.blogspot.co.id/2011/11/krisis-identitas-nasional.html.

Diakses 1 Agustus 2017, pukul. 10.00 WIB.

${ }^{9}$ Lihat Firmanzah, Mengelola Partai Politik: Komunikasi dan Positioning Ideologi di Era Demokrasi, (Jakarta: Yayasan Obor Indonesia, 2018), hlm. 23. 
penelitian ini bertujuan untuk mendapatkan eksplanasi sejarah untuk mengungkapkan konsep nation-state menurut Abdullah Munsyi dalam konstelasi ideologi politik Melayu Islam di abad ke-19 M dan mendeskripsikan relevansinya konsep negara bangsa Indonesia saat ini.

Secara teoritis penelitian diharapkan memberikan kontribusi pemikiran, terutama bagi pelestarian tradisi keilmuan di dunia Melayu. Serta penelitian ini juga bermanfaat untuk memperkaya ide dan gagasan khazanah wawasan tentang kajian ilmu sejarah politik Islam, khususnya politik Islam Melayu serta diharapkan akan memberikan konstribusi berkaitan dengan upaya membangun good governance di Indonesia saat ini tengah carut marut. Secara praktis penelitian ini berguna untuk para sejarawan dalam menulis ulang sejarah Melayu secara ilmiah dan objektif.Lebih, jauh

Penelitian ini mengkaji dan mendeskripsikan pemikiran ideologi politik, khususnya konsep negara bangsa (nation-state) dari intelektual Melayu Islam abad ke-19 M, Abdullah Munsyi. Untuk itu, digunakan teori conscience moraleErnest Renan. MenurutErnest Renan, unsur yang pembentuk negara bangsa ialah: (1). Jiwa atau asas kerohanian yang sama, berupa pandangan hidup dan sistem nilai; (2). Memiliki solidaritas besar, misalnya disebabkan persamaan nasib dalam sejarah; dan (3). Munculnya suatu bangsa merupakan hasil dari sejarah. Di sini,menurut teori Ernest Renan,munculnya negara bangsa karena adanya pandangan hidup dan sistem nilai yang sama. ${ }^{10}$

${ }^{10}$ Lihat Syarif Firmansyah, "Tantangan Penguatan Komitmen Kebangsaan untuk membangun Karakter Warga negara Pada Masyarakat Perbatasan”. Laporan Penelitian, (Jakarta: Universitas Pendidikan Indonesia, 2013); lihat juga Adhyaksa Dault, Islam dan Nasionalisme: Reposisi Wacana Universal Dalam Konteks Nasional (Jakarta: Pustaka Al-Kautsar, 2005), hlm. 2; Abdul Choliq Murod, Nasionalisme Dalam Perspektif Islam,Jurnal Sejarah CITRA LEKHA, Vol. XVI, No. 2 Agustus 2011, hlm. 47. 
Untuk mengungkapkan kesepakatan bersama antar warga negara dan menjaga intergrasi dan identitas jati diri bangsa dalam nation-state, maka penelitian ini juga menggunakan teori kontrak sosial (social contract) yang digagas oleh J.J. Roussaeu. Ia beranggapan bahwa negara dibentuk berdasarkan perjanjian-perjanjian dalam tradisi sosial masyarakat. Teori ini meletakkan negara untuk tidak berpotensi menjadi negara tirani, karena keberadaan suatu negara bersandar pada perjanjian warga negara untuk meningkatkan diri dengan suatu pemerintah yang dilakukan melaluiorganisasi politik. Yangberdaulat adalah rakyat, sedangkan pemerintah melaksanakan mandat bersama tersebut. ${ }^{11}$ Dengan menggunakan teori Ernest Renan dan kontrak sosial (social contract) dari J. J. Roussae akan dikaji konsep nation state Abdullah Munsyi, di mana ia menekankan pentingnya bangsa Melayu hidup bersama yang dibingkai oleh kesepakatan bersama dan menghasilkan hubungan kontraktual terbuka dalam memperjuangkan hak-haknya, baik sosial maupun politik dengan prinsip egaliter dan antiotokratik.

Selain kedua teori di atas, penelitian ini juga menggunakan teori hermeneutika, ${ }^{12}$ terutama hermeneutika yang pernah dikembangkan oleh Hans-Georg Gadamer mengenai hakikat pemahaman manusia, maka untuk memahami nation-state Abdullah Munsyi dapat dilakukan dengan cara; pertama, membangun praanggapan (prejudice) adalah dengan cara melakukan penelitian

${ }^{11}$ Ubaedillah dan Abdul Rozak, Pendidikan Kewarga[negara]an (Civic Education), (Jakarta: Kencana, 2012), hlm. 123-126.

${ }^{12}$ Lihat E. Sumaryono, Hermeneutik: Sebuah Metode Filsafat, (Yogyakarta: Kanisius, 1999), hlm. 23. Penjelasan lebih jauh tentang hermeneutik dapat dibaca karya Josef Bleicher, Hermeutika Kontemporer: Hermeneutika Sebagai Metode, Filsafat dan Kritik, (Yogyakarta: Fajar Pustaka Baru, 2003), hlm. 5-29 dan Richard E. Palmer, Hermeneutika Teori Baru Mengenai Interpretasi, (Yogyakarta: Pustaka Pelajar, 2005), hlm. 3-13. 
kepustakaan yang berkaitan dengan subject matter penelitian ini. Kedua, interpretasi dapat terjadi apabila berlangsung fusion of horizons. Upaya untuk mencapai hal itu adalah dengan cara membandingkan pokok-pokok pemikiran nation-state menurut Abdullah Munsyi dengan referensi lain yang membahas pokok-pokok pemikiran sejenis. Melalui cara dapat dirumuskan relevansi kandungan nation-state yang digagas Abdullah Munsyi dengan sistem politik Islam saat ini.

\section{B. Metode Penelitian}

Sumber data dalam penelitian menggunakan sumber data primer dan sekunder. Data primer adalah data yang dikumpulkan melalui studi pustaka, baik yang berkaitan dengan biografi dan karya tulis Abdullah Munsyi, khususnya kitab Hikayat Abdullah. Namun karena karya asli yang ditulis tangan oleh Abdullah Munsyi sampai peneltitian ini dilaksanakan tidak ditemukan, maka yang dijadikan sumber primer adalah buku Hikayat Abdullahkarya Abdullah Musnyi terbitan Yayasan Karyawan, Kuala Lumpur, Malaysia tahun 2007.Untuk melengkapi data primer, penelitian ini juga menggunakan data sekunder, yakni karya Amin Sweeney berjudulKarya Lengkap Abdullah bin Abdul Kadir Munsyi, Jilid 1-3 yang diterbitkan Kepustakaan Populer Gramedia bekerjasama dengan Ecole francais d'Extreme-Orient, Jakarta tahun 2005 dan 2008. Selain itu, penulis juga menggunakan data sekunder lainnya, baik berupa buku, artikel jurnal, makalah, dan lainya yang berhubungan dengan masalah penelitian.

Pendekatan yang digunakan dalam penelitian ini adalah pendekatan historis dan filsafat politik. Pendekatan historis digunakan untuk mengungkapkan biografi, setting sosio-culutral dan politik di masa Abdullah Munsyi. Sedangkan pendekatan filsafat politik 
digunakan untuk mengkaji pemikiran nation-state Abdullah Munsyi dan kontekstualisasinya di Indonesia saat ini.

Penelitian sejarah yang pada dasarnya adalah penelitian terhadap sumber-sumber sejarah sebagai implementasi dari tahapan kegiatan yang tercakup dalam metode sejarah, yaitu heuristik, kritik, interpretasi, dan historiografi.

\section{Pemikiran Abdullah Munsyi Tentang Politik}

Abdullah bin Abdul Kadir Munsyi adalah seorang keturunan Arab dan Keling. Ayahnya, Syeikh Abdul Kadir, berkebangsaan Arab dan ibunya, Salmah, orang Keling (India). Pada umumnya orang mencatat tahun kelahiran Abdullah bin Abdul Kadir Munsyi pada tahun 1796 dan meninggal pada tahun $1854 .{ }^{13}$ Tetapi menurut I.R. Poedjawijatna, ia dilahirkan pada tahun $1774 .{ }^{14}$ Tempat meninggalnya menurut Datoek Besar dan R. Roolvink ${ }^{15}$ adalah di Makkah, tetapi penulis-penulis yang lain mengatakan di Jedah. ${ }^{16}$

Masa kanak-kanak, Abdullah bin Abdul Kadir Munsyidihabiskan di Malaka. Ia mulai belajar menulis di usia empat tahun dengan "tulisan cakar ayam" di papan tulis. Di usia enam tahun, Abdullah bin Abdul Kadir Munsyi pernah terserang penyakit disentri

\footnotetext{
${ }^{13}$ U.U. Hamidy Raja Hamzah Yunus Tengku Bun Abubakar, Pengarang Melayu Dalam Kerajaan Riau dan Abdullah bin Abdul Munsyi Dalam Sastra Melayu, (Jakarta: Pusat Pembinaan dan Pengembangan Bahasa, Departemen Pendidikan dan Kebudayaan, 1981), hlm. 36.

${ }^{14}$ I.R. Poedjawijatna, Ikhtisar Kesusastraan Indonesia. (Jakarta: Yayasan Obor Indonesia , 1959), hlm. 34.

${ }^{15}$ Datoek Besar dan R. Roolvink, Hikayat Abdullah. (Jakarta: Jambatan, 1953).

${ }^{16}$ Ajib Rosidi, Ikhtisar Sejarah Sastra Indonesia,(Bandung: Binacipta 1969), hlm. 5; Nursinah Supardo, Kesusastraan Indonesia. (Jakarta: Penerbit Fasco 1956), hlm. 43; Zuber Usman, Kesusastraan Lama Indonesia. (Jakarta: Gunung Agung.1963), hlm. 10.
} 
dan di usia tujuh tahun tak kala teman-teman sebayanya sudah bisa melagukan ayat-ayat al-Quran, namun ia masih belum bisa membaca al-Quran. Justru ia belajar meniru tulisan-tulisan berbahasa Arab dengan penanya. Akibatnya, ayahnya, Abdul Kadir, yang geram melihat keterbelakangan anaknya, sehingga mengirim Abdullah ke Sekolah Qur'an Kampung Pali (Kampong Pali Koran School).

Di masa Sekolah Qur'an Kampung Pali, Abdullah bin Abdul Kadir Munsyi harus belajar dengan keras di bawah bimbingan dan pengawasan ayahnya langsung. Abdul Kadir sendiri memang seorang yang berwatak keras. Di usianya yang kesebelas tahun, Abdullah memperoleh uang sebagai upah pekerjaannya menyalin teks al-Quran dan merupakan pekerjaan yang pertama kali ia lakukan. Dari sinilahdapat dikatakan sebagai titik awal bagi karirnya. Tiga tahun kemudian ia mengajar agama bagi sebagian besar tentara muslim yang ditempatkan di Benteng Malaka. Tentara menyebutnya "munsyi", istilah Melayu untuk guru bahasa, gelar yang kemudian tersemat kepadanya hingga akhir hidupnya. Didikan ayahnya yang keras dalam bidang agama dan pengetahuan umum mengantarkannya menjadi seorang guru bahasa dan mampu menguasai berbagai bahasa, di antaranya bahasa Arab, Tamil, India, Inggris, dan Melayu.

Meskipun Abdullah bin Abdul Kadir Munsyi merupakan peranakan Arab dan Tamil, namun dibesarkan di tengah budaya Melayu di Melaka, yang pada saat itu baru saja dijajah Britania (Inggris). Pada awalnya Abdullah mengajarkan bahasa Melayu kepada tentara keturunan India di garnisun Malaka, dan kepada para misionaris, pegawai dan pebisnis Britania dan Amerika Serikat. Ia juga pernah bekerja untuk Thomas Stamford Raffles sebagai juru tulis, menerjemahkan Injil serta teks agama Kristen lainnya untuk London Missionary Society di Malaka, dan menjadi pencetak untuk American Board of Missions di Singapura. 
Dalam perjalanannya hidupnya, Abdullah bin Abdul Kadir Munsyi pada awalnya tinggal di Malaka, selanjutnya setelah berdiri Singapura, ia pindah ke sana. Sungguhpun alasan pertama mengenai kepindahan Abdullah bin Abdul Kadir Munsyi ke Singapura untuk menghilangkan kesedihannya karena istrinya baru saja meninggal di Malaka. Namun, ditinjau dari jalan hidupnya sebenarnya karena Inggris telah menyerahkan Malaka kepada Belanda dan kemudian Raffles membuka kota Singapura. Kedatangan Belanda ke Malaka menggantikan Inggris tidak memberikan iklim yang baik bagi Abdullah bin Abdul Kadir Munsyi--demikian juga terhadap sebagian besar penduduk Malaka yang lain--karena Abdullah bin Abdul Kadir Munsyi tidak menguasai bahasa Belanda. Tampaknya Belanda tidak memerlukan orang-orang yang ahli dalam bidang bahasa, seperti Abdullah bin Abdul Kadir Munsyi. ${ }^{17}$

Dalam hubungan saling mengisi itulah Abdullah bin Abdul Kadir Munsyi memperoleh nafkah untuk memenuhi kehidupannya, yakni sebagai guru bahasa, penerjemah, dan informan bagi orang Inggris. Raffles dan kawan-kawannya dapat mengetahui masyarakat Melayu dan dunianya. Mereka bukan hanya memerlukan ilmu pengetahuan, melainkan terlebih-lebih untuk kepentingan kekuasaan Inggris. Karena eratnya hubungan Abdullah bin Abdul Kadir Munsyi dengan pihak Inggris, terutama Raffles, sehingga Datoek Besar dan R. Roolvink sampai mengatakan bahwa Abdullah bin Abdul Kadir Munsyi seolah-olah "boneka" Inggris. Rasanya dapat pula dikatakan, jika tidak ada Inggris tidak ada Abdullah bin Abdul Kadir Munsyi. ${ }^{18}$

${ }^{17}$ Lihat Rina Rehayati dan Irzum Farihahi, "Transmisi Islam Moderat Oleh Raja Ali Haji di Kesultanan Riau-Lingga pada Abad Ke-19”. Dalam Jurnal Ushuluddin, Vol. 25 No.2, Juli-Desember, (Yogyakarta: UIN Sunan Kalijaga, 2017), hlm.181.

${ }^{18}$ Datoek Besar dan R. Roolvink, Hikayat Abdullah, hlm. xii. 
Pekerjaannya sebagai guru bahasa bagi orang-orang Inggris, Abdullah bin Abdul Kadir Munsyi mendapat kesempatan belajar bahasa Inggris dari orang-orang Inggris. Ia belajar bahasa Inggris terutama kepada Tuan Milne, salah seorang guru Anglo College di Singapura. Kemampuan Abdullah bin Abdul Kadir Munsyi dalam bahasa Inggris semakin memperluas kegiatannya dalam bidang bahasa dan sastra. Bersama Tuan Thomsen, mereka menerjemahkan kitab Injil Matius dan Kisah Segala Rasul-rasul. Bersama dengan Paderi Keasberry diterjemahkan kitab Henry dengan pengasuhnya ke dalam bahasa Melayu. Dalam usaha menerjemahkan kitab Injil itu, Abdullah bin Abdul Kadir Munsyi mengkritik bahasa Melayu yang dipakai oleh penerjemah Injil yang terdahulu. Kata-kata, seperti berkesemauan, berkejabatan, menurut Abdullah bin Abdul Kadir Munsyi terlalu janggal atau canggung dalam bahasa Melayu, sehingga seperti antan dicongkilkan duri. Ungkapan anak Allah, kerajaan surga, mulut Allah, dan bapamu yang ada di surga, menurut Abdullah bin Abdul Kadir Munsyi adalah bentuk-bentuk yang canggung di telinga orang Melayu. ${ }^{19}$

Abdullah bin Abdul Kadir Munsyi memandang bahasa sebagai suatu ilmu yang amat penting. Bahasa baginya merupakan titik api kegiatan hidup manusia karena sesungguhmya, menurut Abdullah bin Abdul Kadir Munsyi, bahasa itu membuat manusia berakal dan memperkaya khazanah keilmuan. ${ }^{20}$ Di sisi pandangan Abdullah bin Abdul Kadir Munsyi yang seperti itu, ia berulang-ulang mengkritik dan mengecam orang-orang Melayu yang tidak mau memperhatikan dan mempelajari bahasa dan kebudayaannya.

\footnotetext{
${ }^{19}$ Ibid., hlm. 38.

${ }^{20}$ Datoek Besar dan R. Roolvink, Hikayat Abdullah, hlm. 321.
} 
Kegiatan Abdullah bin Abdul Kadir Munsyi dalam bidang kesusastraan tentu berpangkal dan sangat banyak ditentukan oleh kegiatannya dalam bidang bahasa. Dalam bidang kesusastraan inilah tampaknya Abdullah bin Abdul Kadir Munsyi jauh lebih menonjol. Karena itu, tak mengherankan jika disebut bidang kesusastraan ini, menempatkan Abdullah bin Abdul Kadir Munsyi sebagai tokoh pembaru yang amat penting dalam abad ke-19 M.

Melalui karya-karyanya yang dipandang memakai bahasa sehari-hari, atau mendekati bahasa Indonesia sekarang, berkisar dari fantasi tentang raja-raja dengan putri-putri yang cantik kepada kehidupan sehari-hari. Oleh karena itu, para penulis buku kesusastraan (Indonesia), Abdullah bin Abdul Kadir Munsyi dipandang telah mengubah kesusastraan kuno menjadi kesusastraan baru. Sebagai akibat penilaian yang demikian, Abdullah bin Abdul Kadir Munsyi menjadi semacam garis pemisah antara kesusastraan kuno dan kesusastraan baru. Ia adalah fajar zaman baru, demikian ungkap Zuber Usman. Karena Abdullah meninggalkan yang bercorak tradisional dan bergerak ke arah yang rasional, sehingga bagi Burton Raffel, ${ }^{21}$ Abdullah bin Abdul Kadir Munsyi dipandang sebagai Bapak SastraMelayu Modern. ${ }^{22}$

Setidaknya terdapat empat (4) aspek penting yang terangkum pada pemikiran Abdullah bin Abdul Kadir Munsyi dalam karyanya berjudul Hikayat Abdullah ini, yakni bidang ekonomi, sosial, politik dan agama yang terkandung di dalam setiap bab di dalam hikayat ini.

${ }^{21}$ U.U. Hamidy Raja Hamzah Yunus Tengku Bun Abubakar, Pengarang Melayu dalam Kerajaan Riau dan Abdullah Bin Abdul Kildir Munsyi dalam Sastra Melayu, hlm. 38.

${ }^{22}$ Lihat artikel Jan van der Putten, "Abdullah Munsyi dan Misionaris". Dalam Jurnal Bijdragen tot de Taal, Vol. 162, No. 4, (Koninklijk Instituut voor taal-, Landen Volkenkunde, (BKI) 162-4 2006), hlm. 407-440. 
Dalam hal politik, khususnya sistem pemertintahan, Abdullah mengulas dan mengkritik sistem pemerintahaan monarki. Masyarakat Melayu menganut sistem pemerintahan monarki absolut di mana kekuasaan berada di tangan raja, tanpa batas. Dalam sistem pemerintahan monarki absolut berprinsip seorang raja mempunyai kuasa penuh untuk memerintah negaranya dan rakyat harus mentaati perintah raja sepenuh hati. Artinya, sistem pemerintahan monarki absolut adalah kekuasaan politik dan hukum berada di tangan raja sebagai pemegang kekuasaan tertinggi. Banyak kisah-kisah yang menceritakan hukuman para raja yang tidak adil atau tidak masuk akal. Di antaranya seperti di bawah ini;

"Maka setelah sudah berkampung, maka Tuan Raffles pun duduklah dia atas tempat bicara itu, katanya, "Tuan Sultan dan Temenggung, bagaimanakah adat dalam undang-undang orang Melayu, jikalau seorang rakyat menderhaka kepada rajanya demikian ini?" Maka jawab Sultan , "Tuan kalau adat Melayu, orang itu dibunuh habis-habis dengan anak bininya dan kaum keluarganya. Maka tiang rumahnya dibalikkan dan ke atas dan bumbung rumahnya ke bawah dan tanah bekas rumahnya itu pun dibuangkan ke laut,adanya". ${ }^{23}$

Abdulah bin Abdul Kadir Munsyi memaparkan pemikiran terhadap golongan feodal, bangsawan dan raja yang zalim. Abdullah Munsyi menunjukkan sikap benci dan menganggap budaya raja-raja Melayu sebagai kolot dan tidak adil. Ia menganggap raja-raja Melayu sangat zalim karena kehendak mereka tidak boleh dihalangi atau dilarang. Sebab jika dilarang berdampak buruk pada dirinya sendiri. Sikap dan pemikirannya yang tidak senang pada kehidupan feodalistik

\footnotetext{
${ }^{23}$ Ibid., hlm. 180.
} 
raja-raja Melayu yaitu mengenai struktur pendelegasian kekuasaan sosiopolitik yang dijalankan kalangan bangsawan/monarki untuk mengendalikan berbagai wilayah yang diklaimnya melalui kerja sama dengan pemimpin-pemimpin lokal sebagai mitra seperti gambaran tentang Sultan Hussin yang dikatakan gemuk dan kuat makan.

Di samping itu, Abdullah juga sangat menentang perilaku elit kerajaan yang sangat sewenang-wenang dengan rakyatnya. Sebagai contoh bila seorang raja ingin mempersunting seorang gadis, maka ia akan memaksa gadis tersebut menjadi gundik mereka. Bahkan, terdapat juga gadis-gadis yang dinikahi dengan paksa. Adat atau undang-undang yang mengatakan tidak boleh mendurhakai raja menyebabkan khatib terpaksa menikahkan juga gadis dengan raja mereka.

Abdullah bin Abdul Kadir Munsyi termasuk salah seorang sastrawan Melayu yang cukup produktif menulis. U.U. Hamidy, Raja Hamzah Yunus,dan Tengku Bun Abubakar mencatat di antara karyakarya Abdullah Munsyi, di antaranya; 1).HikayatAbdullah; 2).Sejarah Melayu, 3).Hikayat Panja Tanderan, 4).Syair Singapura Dimakan Api, 5).Kisah Pelayaran Abdullah dari Singapura ke Kelantan, 6).Kisah Pelayaran Abdullahke Negeri Jeddah. ${ }^{24}$

\section{Temuan dan Pembahasan Hasil Penelitian}

Paham teokrasi-monarki bangsa Melayu membuat Abdullah bin Abdul Kadir Munsyi “gerah”, sehingga memunculkan perlawanan melalui karya-karya sastranya yang mengkritik perilaku para raja Islam Melayu yang dalam terminologi politik modern disebut

\footnotetext{
${ }^{24}$ U.U. Hamidy, Raja Hamzah Yunus, dan Tengku Bun Abubakar, Pengarang Melayu Dalam Kerajaan Riau dan Abdullah bin Abdul Munsyi Dalam Sastra Melayu, hlm.39-43.
} 


\section{Andi Chandra Jaya: KONSEP NATION STATE .....}

monarchomach atau penentang raja/anti kerajaan.Banyak kisah yang diceritakan Abdullah bin Abdul Kadir Munsyi mengenai raja yang tidak adil atau tidak masuk akal. Di antaranya seperti di bawah ini;

"Maka setelah sudah berkampung, maka Tuan Raffles pun duduklah dia atas tempat bicara itu, katanya, "Tuan Sultan dan Temenggung, bagaimanakah adat dalam undang-undang orang Melayu, jikalau seorang rakyat menderhaka kepada rajanya demikian ini?" Maka jawab Sultan , "Tuan kalau adat Melayu, orang itu dibunuh habis-habis dengan anak bininya dan kaum keluarganya. Maka tiang rumahnya dibalikkan dan ke atas dan bumbung rumahnya ke bawah dan tanah bekas rumahnya itu pun dibuangkan ke laut,adanya". ${ }^{25}$

Abdullah Munsyi menunjukkan sikap benci dan menganggap budaya raja-raja Melayu sebagai kolot dan tidak adil. Ia menganggap raja-raja Melayu sangat zalim karena kehendak mereka tidak boleh dihalangi atau dilarang. Sebab jika dilarang berdampak buruk pada dirinya sendiri. Sikap dan pemikirannya yang tidak senang pada kehidupan feodalistik raja-raja Melayu, seperti gambaran tentang Sultan Hussin yang dikatakan gemuk dan kuat makan. Selain itu, Abdullah juga turut mengatakan Sultan Hussin bodoh karena menolak tawaran Tuan Raffles yang menginginkan anak Sultan belajar ke Benggala supaya belajar pelbagai jenis ilmu pengetahuan. Kritikan ini dapat dilihat berdasarkan petikan;

"Bahawa sesungguhnya adalah pada fikiranku maka nyatalah kebodohan dan kekurangan fikiran Sultan itu, maka alangkah baik dan besar tolongan Tuan Raffles itu hendak mengajarkan anak-

${ }^{25}$ Abdullah Abdul Kadir Munsyi, Hikayat Abdullah, (Kuala Lumpur: Yayasan Karyawan, 2007), hlm. 180. 


\section{Andi Chandra Jaya: KONSEP NATION STATE .....}

anak mereka itu supaya kemudian kelak ia boleh mengerti dan mendapat kepandaian dan hikmah akan menambahkan akal dan pengetahuan." 26

Di samping itu, Abdullah juga sangat menentang perilaku elit kerajaan yang sangat sewenang-wenang dengan rakyatnya. Sebagai contoh bila seorang raja ingin mempersunting seorang gadis, maka ia akan memaksa gadis tersebut menjadi gundik mereka. Bahkan, terdapat juga gadis-gadis yang dinikahi dengan paksa. Adat atau undang-undang yang mengatakan tidak boleh mendurhakai raja menyebabkan khatib terpaksa menikahkan juga gadis dengan raja mereka.

"Syahadan lagi, hendaklah tuan-tuan mendengar ada lagi suatu ajaib yang kudengar, kecualinya ada raja-raja Melayu yang membuat sesuatu adat, iaitu bukannya adat orang Islam dan bukannya adat bangsa-bangsa lain pun yang ada di dunia, melainkan adat iblis atau adat hawa nafsu yang jahat, iaitu kalau raja-raja mengambil anak-anak perempuan orang kebanyakan hendak dibuat gundik itu dengan kerasnya, semata-mata tiada dengan redha perempuan itu, istimewa ibu bapanya maka digagahinya disuruhnya bawa perempuan itu ke rumahnya, maka dipanggilnya khatib atau lebai-lebai yang bebal yang tiada mengetahui hukum agama Islam dan yang tamak akan upah". ${ }^{27}$

Selanjutnya, fakta bahwa Inggris telah mendarat di Singapura mereka telah memberlakukan hukum di Singapura. Undang-undang ini diberlakukan untuk menjamin keamanan negara Singapura dari

\footnotetext{
${ }^{26}$ Ibid., hlm. 187.

${ }^{27}$ Ibid., hlm. 301.
} 


\section{Andi Chandra Jaya: KONSEP NATION STATE}

luar. Ada kutipan yang menceritakan tentang penyusunan negara Singapura dalam Hikayat Abdullah ini;

"Syahadan, setelah ramailah sudah negeri Singapura, maka oleh Tuan Raffles dikarangkannyalah undang-undang,iaitu menyatakan adat-adat dan hukum-hukum yang patut dipakai dalam negeri Singapura supaya terpelihara segala isi negeri daripada segala bahaya dan kejahatan, adanya." 28

Cuplikan bait-bait sastra yang ditulis Abdullah Munsyi dalam Hakayat Abdullah di atas dapat dikatakan sebagai "pergolakan batin" Abdullah bin Abdul Kadir Munsyi melihat kondisi masyarakat Melayu yang diperintah oleh para raja tiran dan tidak adil yang dinilainya bertanggung jawab atas keterbelakangan masyarakat Melayu. Para raja telah merampas hak-hak rakyat dan berbuat segala sesuatu yang penting bagi kehidupan mereka.

Melihat kondisi masyarakat demikian Abdullah bin Abdul Kadir Munsyi menggagas faham kebangsaan (nation-state) Melayu.Melalui karya terpentingnya, Hakayat Abdullah, ia mengedepankan rumusan identitas masyarakat Melayu dalam rumusan bangsa, yang dipahami sebagai suku atau ras Melayu sebagai sebuah komunitas yang sepenuhnya berada di bawah sistem kekuasaan politik yang berbasis pada ideologi kerajaan. Melainkan sebagai sebuah ras atau bangsa yang memiliki hak untuk terlibat menentukan format politik Melayu. ${ }^{29}$

${ }^{28}$ Ibid., hlm. 198.

${ }^{29}$ Jajat Burhanuddin, "Tradisi Keilmuan dan Intelektual", dalam Taufik Abdullah (ed, et all), Ensiklopedi Tematis Dunia Islam Asia Tenggara, Jilid 5, (Jakarta: Ichtiar Baru Van Hoeve, 2002), hlm. 162. 
Bangsa dalam terminologi Abdullah Munsyi mengacu kepada rakyat (common people). Artinya, konsep bangsa dalam pemahaman Abdullah bin Abdul Kadir Munsyi memiliki nilai egalitarian. Hal ini sangat kontras dengan bangsa yang dipahami dari ideologi kerajaan (monarki) yang sangat elitis dan aristokratis.Sebab doktrin kesetaraan (egalitarianisme) merupakan hal yang menjadi barang berharga bagi kehidupan Indonesia saat ini. Munculnya konflik tuntutan kesetaraan gender, konflik jihad dengan kekerasan, konflik pertikaian antar ras dan agama, dan konflik lainya, merupakan imbas dari sikap manusia yang dijiwai oleh prasangka kebenaran tunggal.

Dalam rangka menghindari berbagai konflik dan menumbuhkan sikap egalitarianisme dalam masyarakat Indonesia gagasan nation-state yang digagas Abdullah Munsyi pada abad ke-19 M lalu, masih tetap aktual dalam konteks masyarakat Indonesia saat ini. Meskipun pemikiran politik Abdullah Munsyi cenderung liberal. Namun setidaknya banyak menekankan pentingnya bangsa Melayu memperjuangkan hak-haknya baik sosial maupun politik mereka. Ia banyak mengkritik ideologi politik kerajaan yang telah membuat kekacauan karena raja-rajanya telah berbuat tiran dan tidak adil. ${ }^{30}$ Menurut pemikirannya konsep kebangsaan adalah komunitas bangsa Melayu yang merupakan bangunan sosial bagi masyarakat di mana prinsip yang dianut bersifat egaliter dan antiotokratik. ${ }^{31}$

Dalam perspektif ilmu ketatanegaraan, konsep negara bangsa (nation-state) yang digagas Abdullah Munsyi merupakan konsep

${ }^{30}$ Daniel Arif Budiman, "Ideologi Politik Melayu Abad ke-19 (Studi Komparasi Pemikiran Abdullah bin Abdul Kadir Munsyi dan Raja Ali Haji), Skripsi, (Yogyakarta: Fakultas Adab dan Humaniora, Universitas Islam Negeri Sunan Kalijaga, 2010), hlm.3.

${ }^{31}$ Lihat Jajat Burhanuddin, "Tradisi Keilmuan dan Intelektual”, hlm. 161-162164. 
tentang negara modern yang terkait erat dengan paham kebangsaan atau nasionalisme. Nasionalisme dapat dikatakakansebagai sebuah situasi kejiwaan dimana kesetiaan seseorangsecara total diabdikan langsung kepada negara bangsa atasnama sebuah bangsa. Dengan demikian, nasionalisme sangat penting sekali bagi bangsa Indonesia untuk bisa menjadi bangsa yang maju, bangsa yang modern, bangsa yang aman dan damai, adil dan sejahtera.

\section{Kesimpulan}

Abdullah bin Abdul Kadir Munsyi atau yang lebih dikenal dengan Abdullah Munsyi adalah penggagas paham kebangsaan. Melalui karya terpentingnya, Hikayat Abdullah, ia mengedepankan rumusan identitas Melayu dalam rumusan bangsa yang dipahami sebagai suku atau ras Melayu. Ia menekankan bahwa bangsa Melayu sebagai sebuah komunitas yang memiliki hak untuk terlibat menentukan format politik Melayu bukan sebagai komunitas yang berada di bawah sistem politik yang berbasis pada ideologi kerajaan yang cenderung otoriter.

Sesuai dengan teori conscience morale Ernest Renan dan teori kontrak sosial (social contract) yang digagas oleh J. J. Roussae, Abdullah bin Abdul Kadir Munsyi penggagas paham kebangsaan. Melalui karya terpentingnya, Hikayat Abdullah, ia mengedepankan rumusan identitas Melayu dalam rumusan bangsa yang dipahami sebagai suku atau ras Melayu yang memiliki hak untuk terlibat menentukan format politik Melayu bukan sebagai komunitas yang berada di bawah sistem politik yang berbasis pada ideologi kerajaan yang cenderung otoriter.

Kedekatannya dengan pihak kolonial Inggris, sehingga membentuk pemikiran liberal yang diperolehnya dari Raffles dan kawan-kawannya. Ia tidak hanya membongkar manipulasi ideologi 
kerajaan, tetapi sekaligus mengedepankan pandangan baru tentang eksistensi individu yang humanis. Paham kebangsaannya memiliki nilai egalitarian yang sangat relevan dengan konteks Indonesia saat ini, khususnya nilai-nilai kesetaraan (egalitarianisme) di tengah munculnya konflik berbagai konflik saat ini. Demikian juga konsep nation-state terkait erat dengan nasionalisme dan good governance di mana pengelolaan pemerintahan yang baik, yang bertumpu kepada kemutlakan adanya transparansi, partisipasi terbuka, dan pertanggung jawaban di dalam semua kegiatan kenegaraan di setiap jenjang pengelolaan negara, sehingga terbentuk pemerintahan yang bersih..

\section{Daftar Pustaka}

Murod, Abdul Choliq, Nasionalisme Dalam Perspektif Islam,Jurnal Sejarah CITRA LEKHA, Vol. XVI, No. 2 Agustus 2011.

Munsyi, Abdullah Abdul Kadir, Hikayat Abdullah, Kuala Lumpur: Yayasan Karyawan, 2007.

Dault, Adhyaksa, Islam dan Nasionalisme: Reposisi Wacana Universal Dalam Konteks Nasional, Jakarta: Pustaka AlKautsar, 2005.

Rosidi, Ajib, Ikhtisar Sejarah Sastra Indonesia, Bandung: Binacipta 1969.

Sweeney, Amin, (ed), Karya Lengkap Abdullah bin Abdul Kadir Munsyi Jilid 3 Hikayat Abdullah, Jakarta: Kepustakaan Populer Gramedia, 2009.

Sweeney, Amin, Karya Lengkap Abdullah bin Abdul Kadir Munsyi, Jilid 1-3, Jakarta: Kepustakaan Populer Gramedia bekerjasama dengan Ecole francais d'Extreme-Orient, 2005.

Budiman, Daniel Arif, "Ideologi Politik Melayu Abad ke-19 (Studi Komparasi Pemikiran Abdullah bin Abdul Kadir Munsyi dan 


\section{Andi Chandra Jaya: KONSEP NATION STATE}

Raja Ali Haji), Skripsi, Yogyakarta: Fakultas Adab dan Humaniora, Universitas Islam Negeri Sunan Kalijaga, 2010

Papp, Daniel S., Contemporary International Relations: Framework for Understanding, London: Macmillan Publishing Company, 2nd edition, 1988.

Datoek Besar, R. Roolvink, Hikayat Abdullah, Jakarta: Jambatan, 1953.

Rosyada, Dede, Pendidikan Kewargaan (Civic Education):

Demokrasi, Hak Asasi Manusia, dan Masyarakat Madani Jakarta: Kencana, 2005.

E. Sumaryono, Hermeneutik: Sebuah Metode Filsafat, (Yogyakarta: Kanisius, 1999.

Firmanzah, Mengelola Partai Politik: Komunikasi dan Positioning Ideologi di Era Demokrasi, Jakarta: Yayasan Obor Indonesia, 2018)

I.R. Poedjawijatna, Ikhtisar Kesusastraan Indonesia, Jakarta: Yayasan Obor Indonesia , 1959.

Burhanuddin, Jajat, "Tradisi Keilmuan dan Intelektual" dalam Taufik

Abdullah (ed), Ensiklopedi Tematik Dunia Islam, Asia Tenggara", Jakarta: Ichtiar Baru Van Hoeve, 2002.

Putten, Jan van der, "Abdullah Munsyi dan Misionaris". Dalam Jurnal Bijdragen tot de Taal, Vol. 162, No. 4, Koninklijk Instituut voor taal-, Land- en Volkenkunde, (BKI) 162-4 2006.

Bleicher, Josef, Hermeutika Kontemporer: Hermeneutika Sebagai Metode, Filsafat dan Kritik, Yogyakarta: Fajar Pustaka Baru, 2003.

Krina, Lalolo, Indikator Dan Tolok Ukur Akuntabilitas, Traansparansi dan Partisipasi, Jakarta: Sekretariat Pengembangan Kebijakan Nasional Tata Kepemrintahan yang Baik, BAPPENAS, 2003. 


\section{Andi Chandra Jaya: KONSEP NATION STATE .....}

Madjid, Nurcholis, Indonesia Kita, Jakarta: Paramadina, 2004.

Supardo, Nursinah, Kesusastraan Indonesia. Jakarta: Penerbit Fasco 1956.

Usman, Zuber, Kesusastraan Lama Indonesia, Jakarta: Gunung Agung.1963.

Palmer, Richard E, Hermeneutika Teori Baru Mengenai Interpretasi, Yogyakarta: Pustaka Pelajar, 2005.

Rina Rehayati, Irzum Farihahi, "Transmisi Islam Moderat Oleh Raja Ali Haji di Kesultanan Riau-Lingga pada Abad Ke-19”. Dalam Jurnal Ushuluddin, Vol. 25 No.2, Juli-Desember, Yogyakarta: UIN Sunan Kalijaga, 2017.

Firmansyah, Syarif, "Tantangan Penguatan Komitmen Kebangsaan untuk membangun Karakter Warga negara Pada Masyarakat Perbatasan". Laporan Penelitian, Jakarta: Universitas Pendidikan Indonesia, 2013.

Abubakar, U. U. Hamidy Raja Hamzah Yunus Tengku Bun, Pengarang Melayu Dalam Kerajaan Riau dan Abdullah bin Abdul Munsyi Dalam Sastra Melayu, Jakarta: Pusat Pembinaan dan Pengembangan Bahasa, Departemen Pendidikan dan Kebudayaan, 1981.

Ubaedillah, Abdul Rozak, Pendidikan Kewarga[negara]an (Civic Education), .Jakarta: Kencana, 2012.

"Krisis

Identitas

Bangsa", dalam http://projectcitizenship.blogspot.co.id/2011/11/krisis-identitasnasional.html. Diakses 1 Agustus 2017, pukul. 10.00 WIB. 